\title{
THE YIELD AND COMPOSITION OF DILL ESSENTIAL OIL IN RELATION TO N=APPLIGATION, SEASON OF CULTIVATION AND STAGE OF HARVEST
}

\author{
D. Tsamaidi1', H.C. Passam¹, D. Daferera², C. Kontopoulou1, T. Karanissa1, I. Karapanos ${ }^{1}$, M. Polissiou ${ }^{2}$ \\ ${ }^{1}$ Agricultural University of Athens, Laboratory of Vegetable Production, lera Odos 75, \\ 11855 Athens, Greece \\ ${ }^{2}$ Agricultural University of Athens, Laboratory of General Chemistry, lera Odos 75, \\ 11855 Athens, Greece
}

\section{INTRODUGTION}

Dill (Anethum graveolens L.) is an annual aromatic herb of the Umbelliferae family, grown widely throughout Europe, America and Asia for use as a fresh herb and for the production of essential oil, which is extensively used by the food industry for flavouring foods and beverages (Clark and Menary 1984)

Studies of aroma composition in dill have concentrated mainly on the seed, which is rich in carvone. Wander and Bouwmeester (1998) reported that dill biomass, seed and carvone yield increased with increasing nitrogen $(\mathrm{N})$ fertilization. Moreover, Singh et al. (1987) concluded that oil content of the whole plant was highest at the time of seed filling after flowering and related to $\mathrm{N}$ application

Dill foliage also contains essential oil, the main component of which is a-phellandrene (Huopalahti and Linko, 1983). Therefore, the aim of the present study was to examine the effect of growth factors ( $\mathrm{N}$-fertilization, season of cultivation and stage of harvest) on plant biomass and the yield and composition of essential oil derived from the foliage.

\section{MATERIALS AND METHODS}

Seeds of dill (Anethum graveolens L cv. Dukat) were sown in October (winter crop) and January (summer crop) and the plants were transplanted to a substrate of peat and perlite $(1: 1 \mathrm{v} / \mathrm{v}) 30$ and 39 days later, respectively. Nitrogen $\left(\mathrm{NH}_{4} \mathrm{NO}_{3}\right)$ was applied weekly at four levels $(50,150,300,450 \mathrm{ppm} \mathrm{N})$ in a completely randomized experimental design. Plant height and leaf number were recorded at harvest, 158 and 83 days after the first and second sowings, respectively. The foliage was weighed and the essential oils were isolated by hydro-distillation in a Clevenger apparatus and analyzed by GC-MS as described for parsley by Petropoulos et al. (2009) using a Rtx$5 \mathrm{MS}$ capillary column $(30 \mathrm{~m} \times 0.25 \mathrm{~mm}$, film thickness $0.25 \mu \mathrm{m})$ with a temperature program gradually increased from $60^{\circ} \mathrm{C}$ to $220^{\circ} \mathrm{C}$ with a rate of $3^{\circ} \mathrm{C} / \mathrm{min}$.

\section{RESULTS}

The plants of the winter crop were taller at harvest than those of the summer crop due to the longer growth period. The foliage fresh weight and number of leaves per plant increased with increasing fertilization in the winter, whereas plant height decreased. By contrast, plant growth was not affected by $\mathrm{N}$ level in the summer.

Table 1: Mean height of plants $(\mathrm{cm})$, leaf number per plant and plant weight $(\mathrm{g})$

\begin{tabular}{|c|c|c|c|c|}
\hline CROP & NITROGEN & PLANT HEIGHT (cm) & LEAF NUMBER PLANT $^{1}$ & WEIGHT (g PLANT $\left.{ }^{1}\right)$ \\
\hline \multirow{4}{*}{ WINTER } & CONTROL (NO) & $130.65 a$ & $6.00 \mathrm{~d}$ & $58.19 d$ \\
\hline & 150 ppm (N1) & $129.16 a$ & $14.47 \mathrm{c}$ & $133.39 \mathrm{c}$ \\
\hline & 300 ppm (N2) & $111.46 \mathrm{~b}$ & $18.45 b$ & $162.48 b$ \\
\hline & 450 ppm (N3) & $104.97 b$ & $21.36 a$ & $186.73 \mathrm{a}$ \\
\hline \multirow{4}{*}{ SUMMER } & CONTROL (NO) & $52.13 a$ & $9.03 \mathrm{ab}$ & $102.51 \mathrm{~b}$ \\
\hline & 150 ppm (N1) & $52.44 a$ & $9.47 a$ & $110.12 b$ \\
\hline & 300 ppm (N2) & $55.00 a$ & $9.47 a$ & $143.74 \mathrm{a}$ \\
\hline & 450 ppm (N3) & $52.47 a$ & $8.91 \mathrm{a}$ & $111.69 b$ \\
\hline
\end{tabular}

The essential oil concentration within the foliage was low $(<0.3 \mathrm{ml} / 100 \mathrm{~g}$ fresh weight). Oil concentration was higher at $300 \mathrm{ppm} \mathbf{N}$ than at the other $\mathbf{N}$ levels in the summer, but was independent of $\mathrm{N}$ application in the winter.

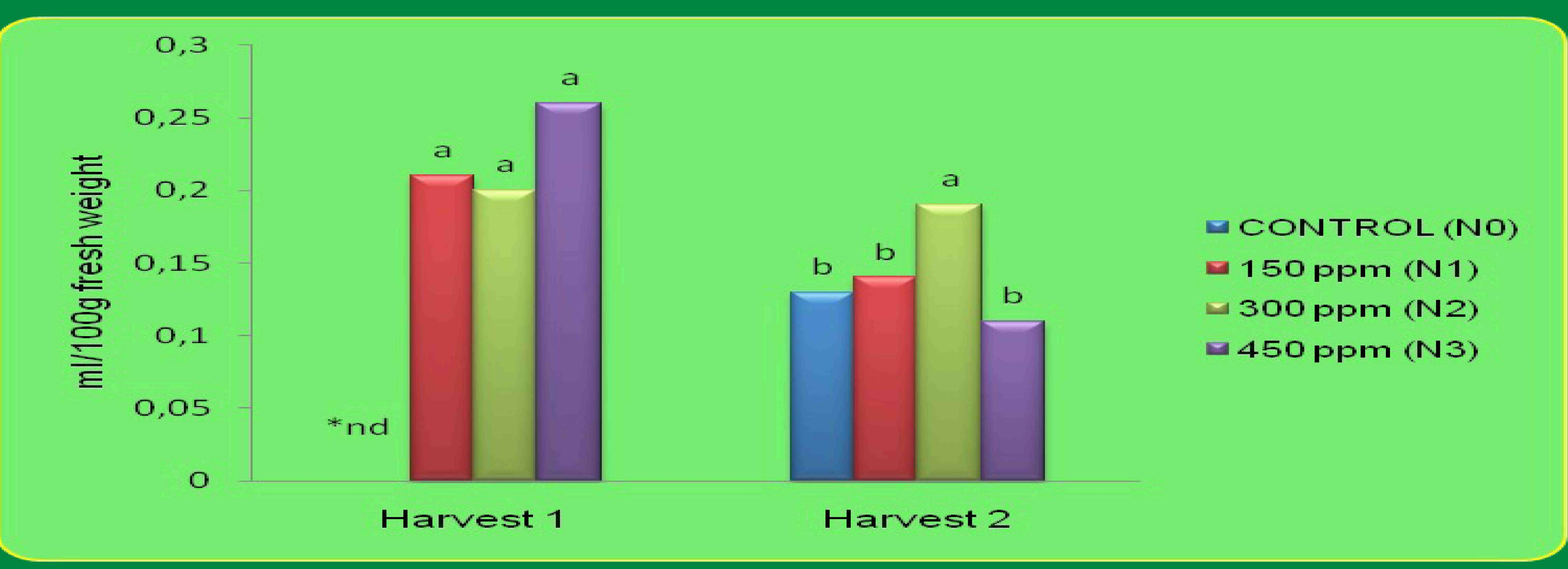

Figure 1: Quantitative analysis of essential oils ( $\mathrm{ml} / 100 \mathrm{~g}$ fresh weight). Means for each harvest with the same letter are not significantly different at $P=0.05$ * nd: not determined.

The main components of the foliar essential oil were $\alpha$-phellandrene, $\beta$-phellandrene dill ether and $\pi$-cymene, followed by $\alpha$-pinene, $\beta$-pinene, $\alpha$-thujene and myrcene,

In both crops a-phellandrene was the principal constituent (Figure 2), while $\beta$ phellandrene, dill ether and $\pi$-cymene had maximum content at 14,21 and $27 \mathrm{mg} / 100 \mathrm{~g}$ fresh matter, respectively (Figures 3-5). The substances a-pinene, $\beta$-pinene, myrcene and $\alpha$-thujene had a maximum content of $2.0,0.06,0.6$ and $0.2 \mathrm{mg} / 100 \mathrm{~g}$ fresh matter respectively.

In the winter crop there was no statistically significant difference in the content of al substances in relation to $\mathbf{N}$ level, although it tended to be higher at $300 \mathrm{ppm} \mathrm{N}$. In the summer crop all the main substances had a higher content at $300 \mathrm{ppm} \mathbf{N}$. Comparing the content between the crops we see that in winter, $\alpha$-pinene, myrcene, $\alpha$-thujene, and $\pi$-cymene had a higher content at 150 and $450 \mathrm{ppm} N$ than in the summer, while $\alpha-$ phellandrene was higher in the summer at $450 \mathrm{ppm} \mathrm{N}$

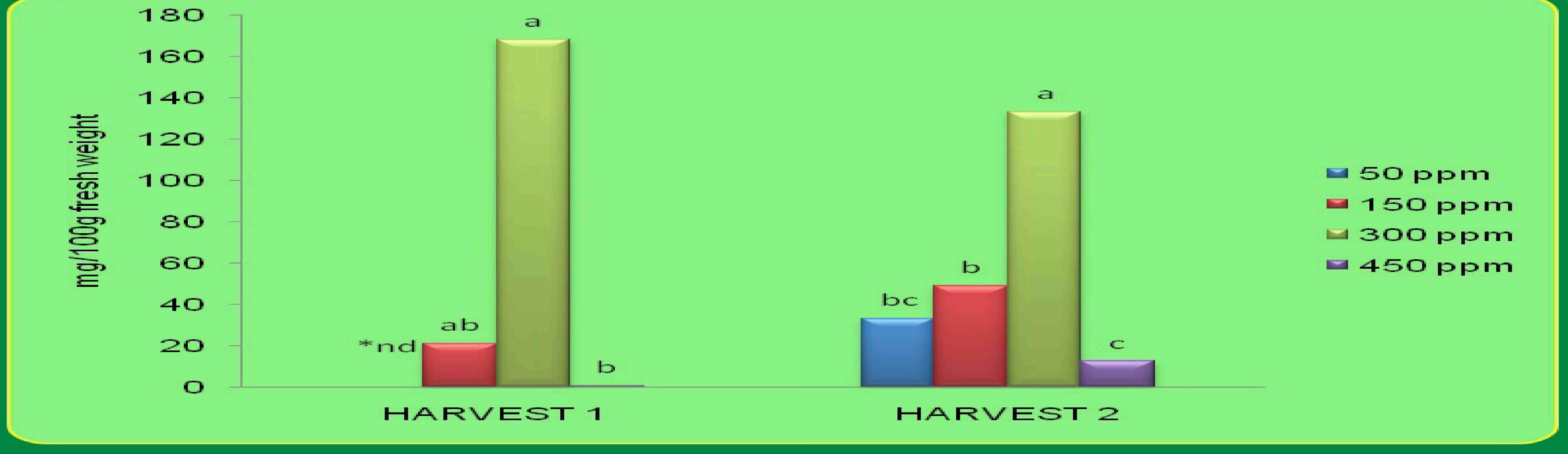

Figure 2. Means of the foliage content of $\alpha$-phellandrene ( $\mathrm{mg} / 100 \mathrm{~g}$ fresh weight). Means for each harvest with the same letter are not significantly different at $P=0.05$. nd: not determined.

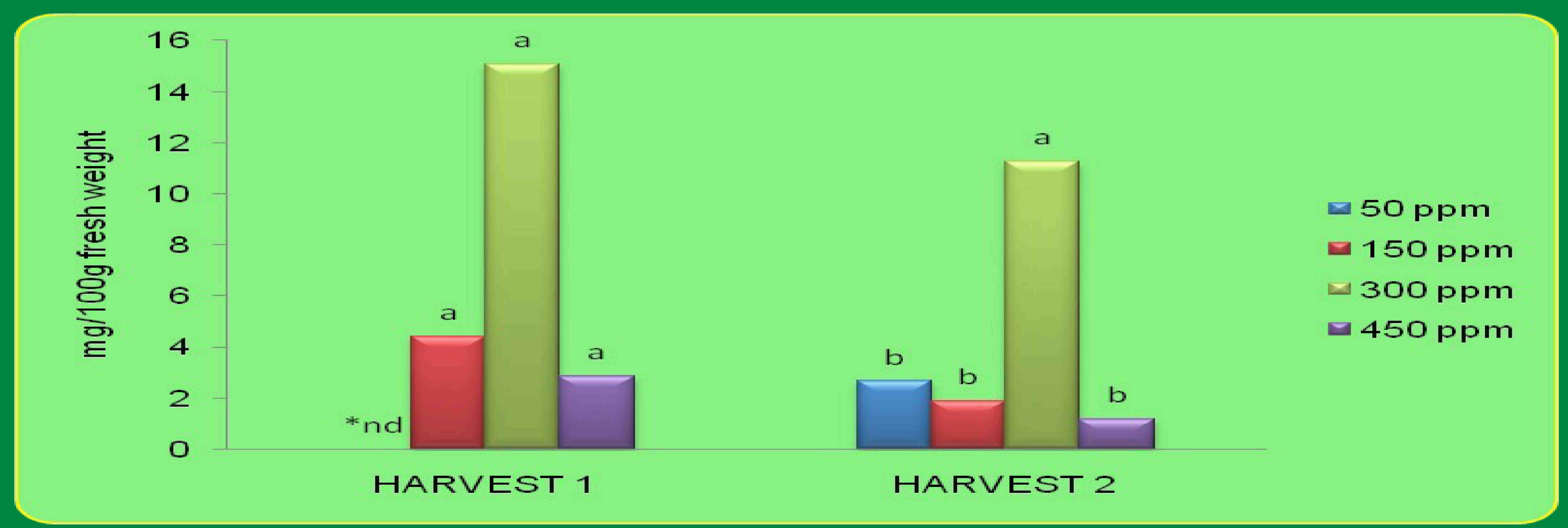

Figure 3. Means of the of the foliage content of $\beta$-phellandrene $(\mathrm{mg} / 100 \mathrm{~g}$ fresh weight). Means for each harvest with the same letter are not significantly different at $P=0.05$. * nd: not determined.

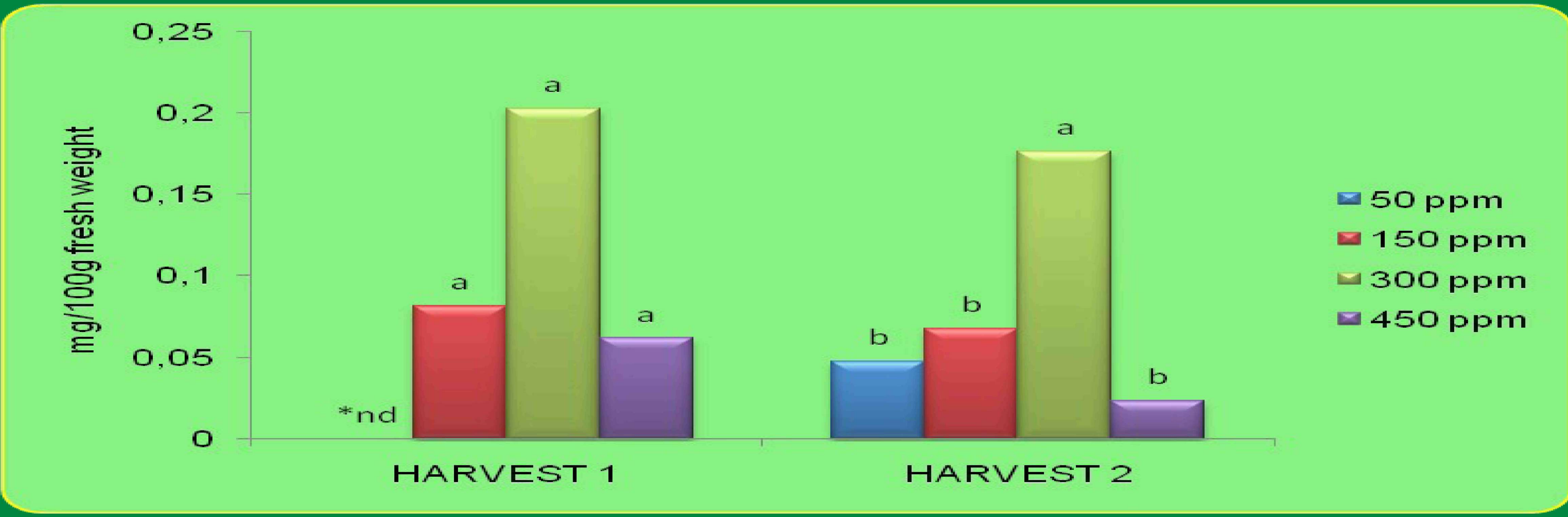

Figure 4. Means of the of the foliage content of dill ether ( $\mathrm{mg} / 100 \mathrm{~g}$ fresh weight)

Means for each harvest with the same letter are not significantly different at $P=0.05$.

nd: not determined.

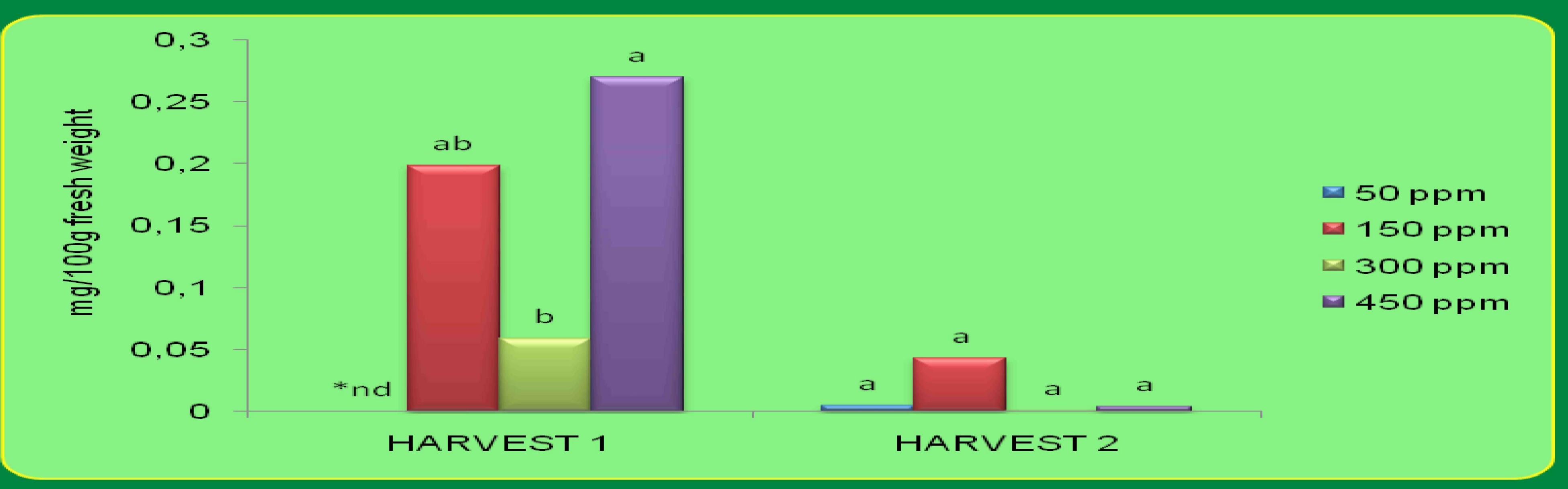

Figure 5. Means of the of the foliage content of $\pi$-cymene $(\mathrm{mg} / 100 \mathrm{~g}$ fresh weight).

Means for each harvest with the same letter are not significantly different at $P=0.05$. ${ }^{*}$ nd: not determined.

\section{GONGLUSION}

Based on the $\mathbf{N}$ rates used here, it is concluded that for a long-cycle winter crop (158 days) $300-450 \mathrm{ppm} N$ is optimal for biomass and foliar oil yield (biomass $\mathrm{x}$ oil concentration) whereas in a shorter summer crop (83 days duration) a lower $\mathrm{N}$ rate may be employed.

\section{AGKNOWLEDGEMENTS}

This research has been co-financed by the European Union (European Social Fund ESF) and Greek national funds through the Operational Program "Education and Lifelong Learning" of the National Strategic Reference Framework (NSRF) - Research Funding Program: Heracleitus II. Investing in knowledge society through the European Social Fund.

\section{REFERENGES}

Clark R.J. and Menary R.C. (1984). The effect of harvest date on the yield and composition of Tasmanian dill oil (Anethum graveolens L.). J. Sci. Food Agric. 35: 1186-1190.

- Huopalahti R. and Linko R.R. (1971). Composition and content of aroma compounds in dill, Anethum graveolens $\mathrm{L}$. at three different growth stages. J. Agric. Food Chem. 31: 331-333

Petropoulos, S.A., Daferera, D., Polissiou, M.G. and Passam, H.C. (2009). The effect of salinity on the growth, yield and essential oils of turnip-rooted and leaf parsley cultivated within the Mediterranean region. J. Sci. Food Agric. 89: 1534-1542.

Singh A., Randhawa G.S. and Mahey R.K. (1987) Oil content and oil yield of dill (Anethum graveolens L.) herb under some agronomic practices. Acta Hort. 208: 51-60.

Wander J.G.N. and Bouwmeester H.J. (1998). Effects of nitrogen fertilization on dill (Anethum graveolens L.) seed and carvone production. Ind. Crops Prod. 7: 211-216. 